\title{
TROUBLESHOOTING OF NITRIFICATION UPSETS AT PHARMACEUTICAL WASTEWATER TREATMENT PLANT
}

\author{
Jurek Patoczka, PhD, PE, Hatch Mott MacDonald \\ 27 Bleeker Str., Millburn, NJ 07041 \\ jurek.patoczka@hatchmott.com
}

\begin{abstract}
A synthetic pharmaceutical manufacturing facility was experiencing recurring upsets of nitrification at its wastewater treatment plant. The main treatment train consisted of trickling filters followed by a conventional activated sludge process with ostensibly adequate treatment capacity (average F/M of 0.1, COD/MLSS-based). An evaluation of the plant's operating conditions and performance indicated that some of the instances of nitrification failure were a direct result of nitrifiers washout due to a nitrogen deficiency followed by increased TKN loads. Ammonia supplementation in an amount adequate to maintain effluent nitrate concentration of $25 \mathrm{mg} / \mathrm{l}$ at all times was implemented with success. In some other instances a lower nitrification efficiency was associated with periods of higher organic loading with likely attendant higher concentration of inhibitory chemicals. Quite expectantly, a number of factors indicated a generally inhibitory nature of the wastewater, with slow nitrification and heterotrophic kinetics. Consequently, a much longer sludge age (lower F/M) than customarily assumed is required to maintain consistent nitrification for such difficult wastewater and measures to address this problem are being implemented.
\end{abstract}

\section{KEYWORDS}

Nitrification inhibition, pharmaceutical wastewater, chemical wastewater, nitrifiers washout, nitrifiers starvation, nitrogen deficiency, ammonia supplementation, ammonification

\section{INTRODUCTION}

The facility is a synthetic pharmaceutical manufacturing plant producing a number of finished products and intermediaries in batch processes in various combinations and production campaigns. The wastewater is treated in a conventional biological wastewater treatment plant prior to discharge to the local stream. The treatment train consists of extensive equalization facilities, trickling filters and a conventional activated sludge process with an average $\mathrm{F} / \mathrm{M}$ of less than $0.2 \mathrm{lb} \mathrm{COD} / \mathrm{lb}$ MLSS-day.

Over a time frame of several years, the plant experienced several periods of elevated effluent ammonia concentrations interspaced with periods of almost complete nitrification. Due to the batch-wise and changing production profile characteristic for the facility, identification of any cause - effect relationship between production profile, raw wastewater composition and treatment efficiency was challenging. An additional cause of concern at the site was the periodically high effluent TSS concentration, despite the use of a synthetic polymer settling aid. 


\section{INVESTIGATIONS}

In addition to a standard review of existing plant operating and performance data to determine relevant trends, correlations and cause-effect relationships, the investigation into the underlying causes of the unreliable nitrification included several other avenues of inquiry, in particular:

- Analysis of wastewater composition from the standpoint of availability of micronutrients.

- Evaluation of the known components of raw wastewater from the standpoint of their biodegradation and potential for nitrification inhibition.

- Laboratory tests of impact on nitrification rate/inhibition of factors such as micronutrients, macronutrients and polymer, $\mathrm{pH}$ and organic loading, among others.

- Microscopic sludge evaluation.

\section{RESULTS AND DISCUSSION}

\section{Nitrogen Deficiency for Nitrification Support}

Based on a detailed analysis of the operational and performance data from episodes of nitrification failure, the primary cause of unreliable and intermittent nitrification on several of the investigated occasions was determined to be insufficient availability of nitrogen over that required for cell synthesis. This caused nitrifiers washout and lack of nitrification capability when ammonia load increased. Re-establishment of a nitrifying population was very slow, and usually occurred only after a period of lower organic loadings. Difficulties in re-establishing nitrifiers were primarily attributed to the inhibitory nature and poor biodegradability of the wastewater mix and its variability inherently associated with the chemical-pharmaceutical production profile at the site. Periodically high organic and ammonia loads imposed additional stress on the treatment process and its ability to re-establish nitrification.

Based on the long-term data, the net sludge yield (heterotrophic) at the biological treatment facility was calculated at a quite low $0.15 \mathrm{~kg}$ MLSS $/ \mathrm{kg}$ COD removed. With the assumed $8 \%$ nitrogen content in the biomass (low sludge age) and COD removed of approximately 3,500 $\mathrm{mg} / \mathrm{l}$, the nitrogen required for heterotrophic growth was approximately $30 \mathrm{mg} / \mathrm{l}$. As indicated on Figure 1, this requirement was periodically not met, resulting in nitrogen deficiency for the purpose of maintaining a viable nitrifiers population.

At this point it should be mentioned that ortho-phosphates in the plant effluent are monitored and phosphoric acid is occasionally added to maintain adequate supply. 
Figure 1 - Nitrification Failure Due to Nitrifiers Wash-out

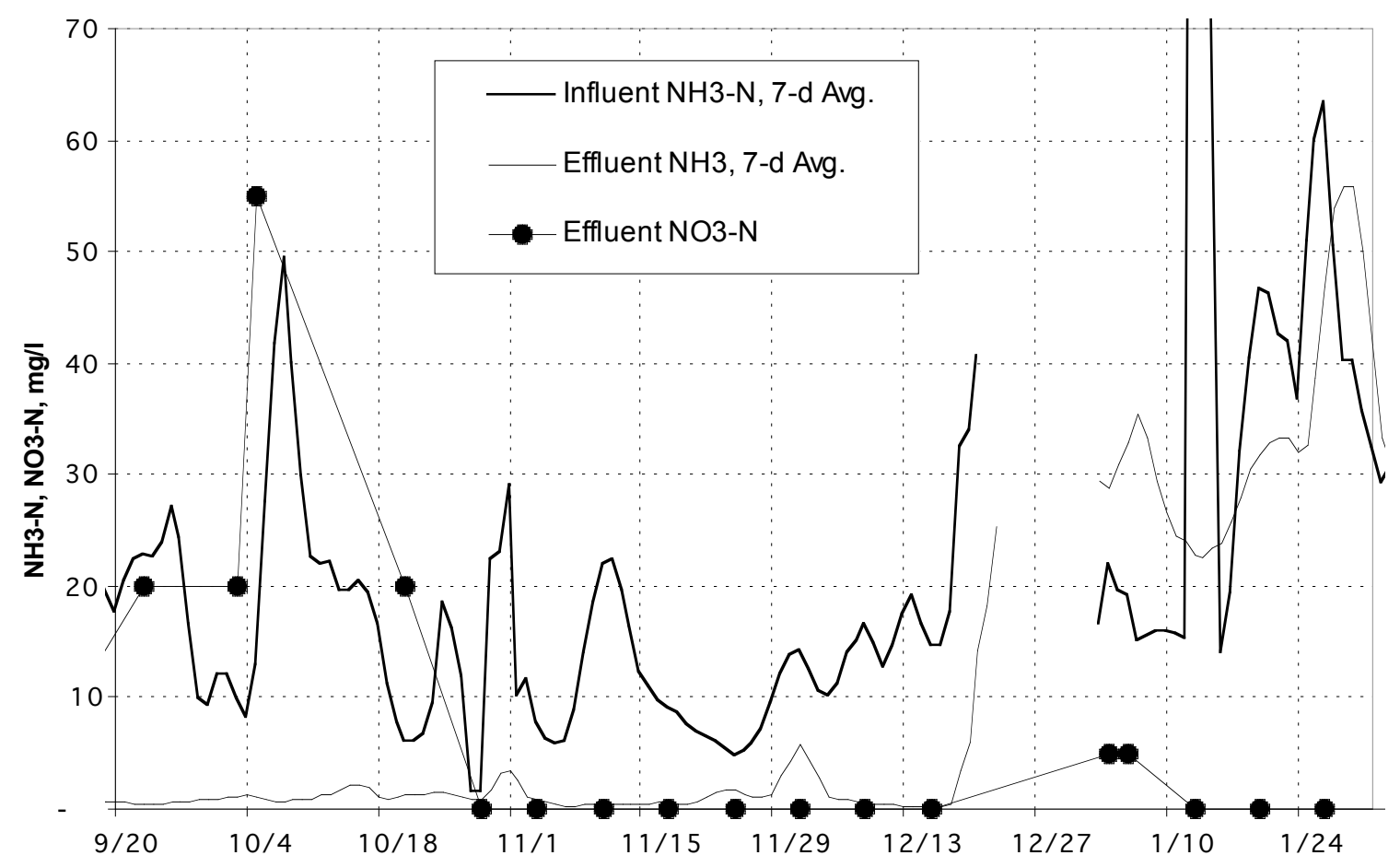

\section{Chemically Specific Inhibition}

As the wastewater originates from synthetic chemicals manufacturing, inhibition was an eminent possibility as a factor impacting nitrification. In order to assess the likelihood of chemically specific nitrification inhibition, a rough estimate of the composition of the raw wastewater for major chemicals potentially present was made, based on simplified assumptions and a mass balance. This exercise indicated that only some of the major volume chemicals, mostly solvents, used at the site were likely present in the raw wastewater at concentrations comparable to the nitrification inhibition thresholds indicated in the literature. Since elimination of these chemicals from the wastewater was not practical, source control was not judged to offer a high promise for a silver bullet solution in terms of eliminating nitrification inhibition effects.

Initially, one of the components of concern was acetonitrile, a common solvent. The acetonitrile itself is only moderately toxic, with an $\mathrm{IC}_{50}$ to Nitrosomonas of $73 \mathrm{mg} / \mathrm{l}$ (Blum and Speece, 1991). However, its nitrile group is a potential precursor of cyanide, which has a low toxicity threshold to nitrification of $0.34 \mathrm{mg} / \mathrm{l}$ (EPA, 1987). Subsequently, it has been established that biological degradation of organic nitriles results in the generation of carboxylic acid (acetic acid in case of acetonitrile) and ammonia (Dhillon and Shivaraman, 1999; Stringfellow, 2003). It is also worth noting that nitrogen in acetonitrile is not measured by the TKN test, which complicates conductance of a nitrogen mass balance. 


\section{Evidence of Slow Degradation Kinetics}

In a multi-component wastewater mixture, distinction between inhibition effects to heterotropic biodegradation and/or to nitrification on one hand and poor biodegradability (slow kinetics) on the other is vague and practically impossible to delineate. Poor biodegradation kinetics of this wastewater were corroborated by several observations:

- The measured nitrification rate in laboratory tests at the plant site was only about $10 \mathrm{mg}$ $\mathrm{NH}_{3}-\mathrm{N}$ oxidized/g MLVSS-day. This is an order of magnitude less than typical values reported at municipal plants (U.S. Environmental Protection Agency, 1993). Consequently, a commensurably higher sludge age may be required at this facility to sustain nitrification than conventionally assumed. Such effects have been previously documented for organic chemicals wastewater (Eckenfelder and Musterman, 1995), where required sludge age of 55 to 60 days at temperature of $10^{\circ} \mathrm{C}$ was indicated.

- The residual, soluble $\mathrm{BOD}_{5}$ from this low-loaded activated sludge system was frequently above $10 \mathrm{mg} / \mathrm{l}$, indicating slow heterotropic kinetics. Periodically, sliding $\mathrm{BOD}_{5}$ results were noted, indicating an inhibition.

- During the periods of stable nitrification, the residual ammonia was typically above 1 $\mathrm{mg} / \mathrm{l}$, more than normally expected.

- Lack of filamentous bacteria and higher life forms was a further indication of an inhibitory, if not toxic, environment.

- During a brief period of unusual temperature drop in the aeration basin to $12^{\circ} \mathrm{C}$ (from a typical winter minimum of $16^{\circ} \mathrm{C}$ ), an immediate spike in ammonia concentration resulted. As such severe sensitivity of nitrification is usually observed at temperatures below $8^{\circ} \mathrm{C}$, the presence of an inhibitory environment was further indicated.

In summary, it was concluded that due to the poor biodegradability and inhibitory nature of the wastewater, and resulting slow nitrification kinetics, a much higher sludge age (lower organic loading) than typically considered adequate was needed to maintain reliable and full nitrification.

\section{Critical Step - Ammonification}

In municipal wastewater, organic amines (mostly urea) undergoes biologically mitigated hydrolysis very quickly, with the residual non-ammonia TKN being no more than $1.5 \mathrm{mg} / \mathrm{l}$ (EPA, 1978) and mostly originating from byproducts of biological metabolism. In such wastewater, the limiting step in the nitrogen removal sequence is normally the subsequent nitrification (or specifically generation of nitrites). In this chemical wastewater the residual, soluble TKN was frequently in double digits (soluble), even with almost complete nitrification (ammonia $<2 \mathrm{mg} / 1)$.

Table 1 presents average data from a 4-day period of incomplete nitrification, including the ammonia profile across the aeration basin (4-zones in series). In that period a relatively small polishing trickling filter (a pilot unit) was used to effect additional nitrification, with some success. However, of most importance in this data is an increasing concentration of ammonia across the aeration basin, which in conjunction with high effluent TKN and nitrates seems to indicate that despite substantial nitrification activity, TKN hydrolysis is incomplete even in the 
last zone of the aeration basin. Source of this recalcitrant TKN and its potential impact on the nitrification performance is a subject of continuing investigation.

\section{Table 1 - Nitrogen Species Profile During Period of Partial Nitrification (mg/l)}

\begin{tabular}{|l|l|l|l|}
\hline Location\Parameter & NH3-N & TKN & NO3-N \\
\hline Influent & 2.6 & & \\
\hline Zone 1 & 7.5 & & \\
\hline Zone 2 & 6.2 & & \\
\hline Zone 3 & 9.2 & & \\
\hline Zone 4 & 13.6 & & \\
\hline Clarifier Effluent & & & 23.7 \\
\hline Polishing TF & 7.7 & & 26.6 \\
\hline Final Effluent & 6.8 & 19.6 & 27.1 \\
\hline
\end{tabular}

\section{Organic Loading}

The impact of the organic loading on the nitrification efficiency at this plant is illustrated on Figure 2, which presents data from the recent period, when nitrogen deficiency was no longer a factor. While the degree of correlation between the COD loading and residual ammonia is likely enhanced by the fact that higher COD loading is typically accompanied by higher ammonia (TKN) loads, the practical conclusion for the plant is that an F/M of less than $0.13 \mathrm{~kg} \mathrm{COD} / \mathrm{kg}$ MLSS-day is a necessary (but not sufficient) condition for achieving full nitrification defined as ammonia of less than $2 \mathrm{mg} / \mathrm{l}$. Interestingly, the effluent ammonia was also correlated with the effluent COD, as presented on Figure 3.

Figure 2 - Correlation Between F/M and Final Effluent NH3

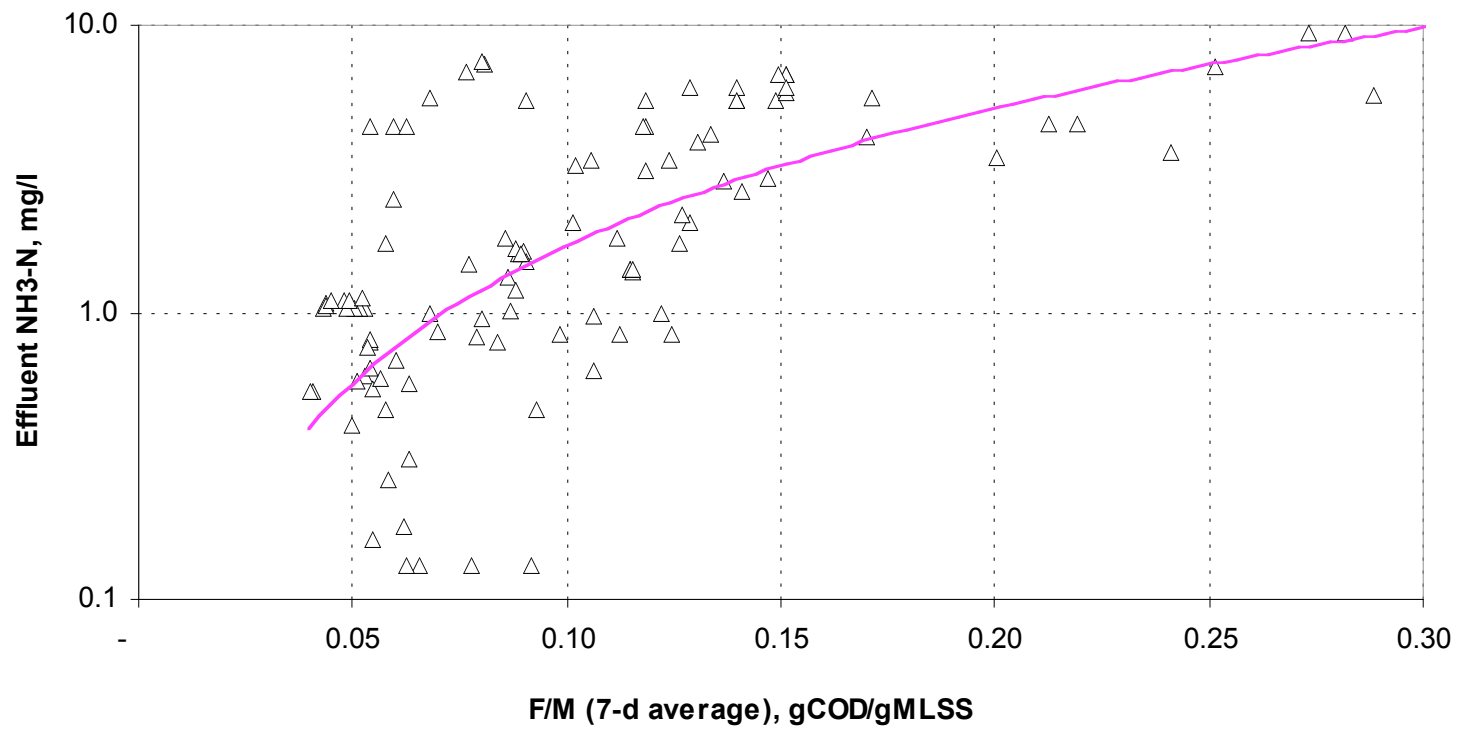


Figure 3 - Correlation Between Effluent COD and NH3

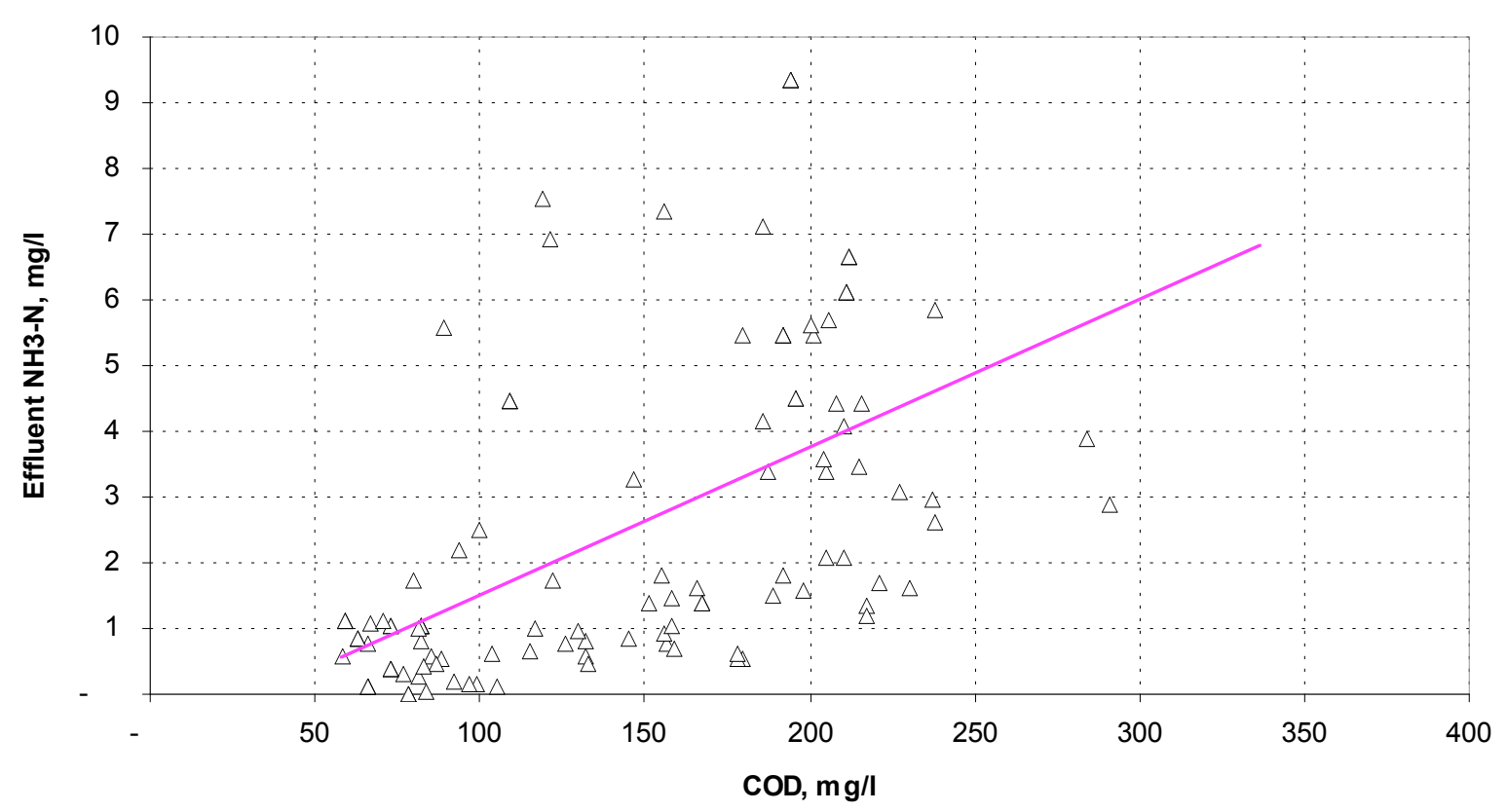

\section{Process pH}

Another factor that had some impact in the periods of lower organic loading was, not unexpectantly, aeration basin $\mathrm{pH}$. The process $\mathrm{pH}$ was not found to be a significant causative factor in periods of nitrification upsets. However, in some periods of operation at relatively low organic loadings, a significant correlation between the effluent $\mathrm{pH}$ and residual ammonia was observed, as illustrated on Figure 4. From that Figure it appears that a $\mathrm{pH}$ of around 7.8 to 8 is optimal, as operation with $\mathrm{pH}$ of above 8 with high residual ammonia could bring the process into the area of nitrification inhibition due to free ammonia toxicity.

To asses the potential for inhibition from unionized ammonia, the fraction of total ammonia present in this toxic form is presented on Figure 5 as a function of the aeration basin $\mathrm{pH}$ and temperature. Knowing that fraction and the concentration of total ammonia, the absolute concentration of free ammonia could be readily calculated and contrasted with the reported lower range of inhibition effects of $0.1 \mathrm{mg} / \mathrm{l}$. 
Figure 4 - Correlation Between Effluent pH and Effluent NH3

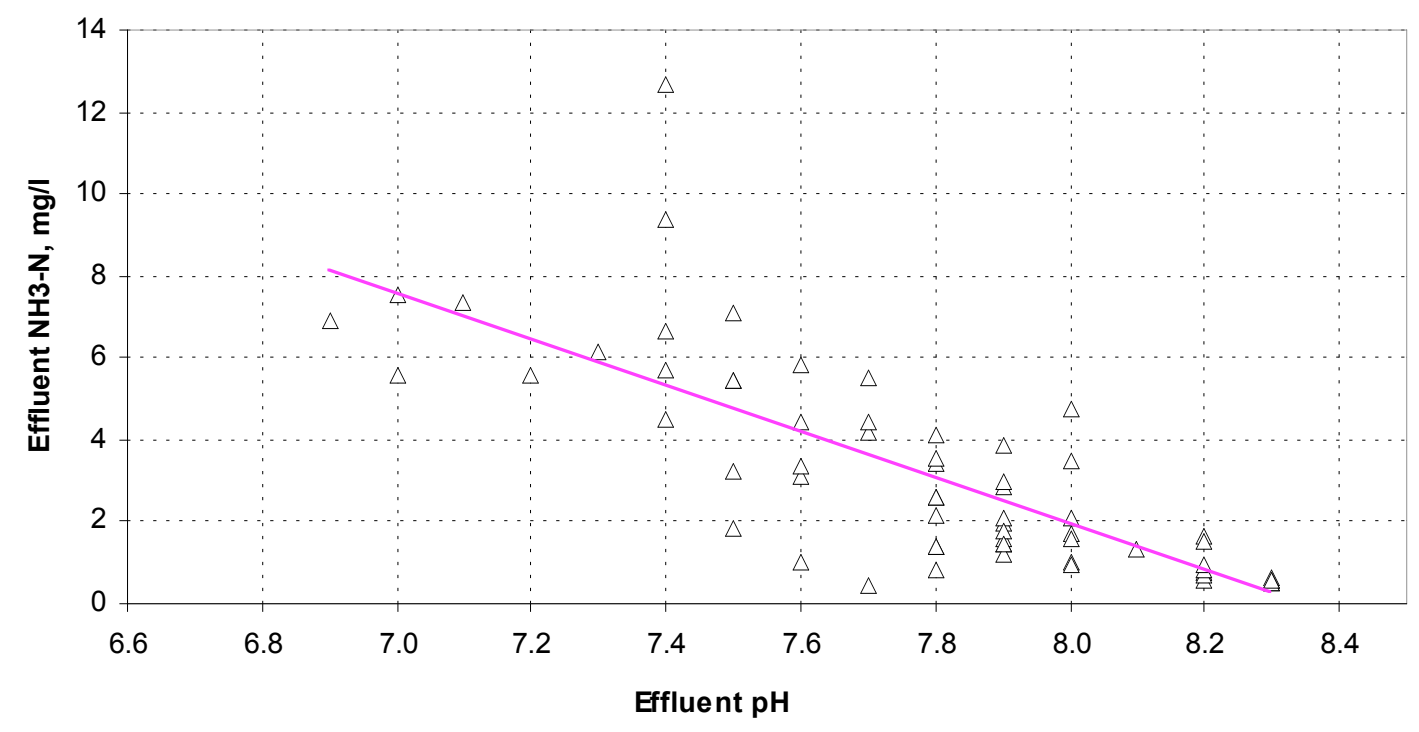

Figure 5 - Free Ammonia Fraction as Function of pH and Temperature

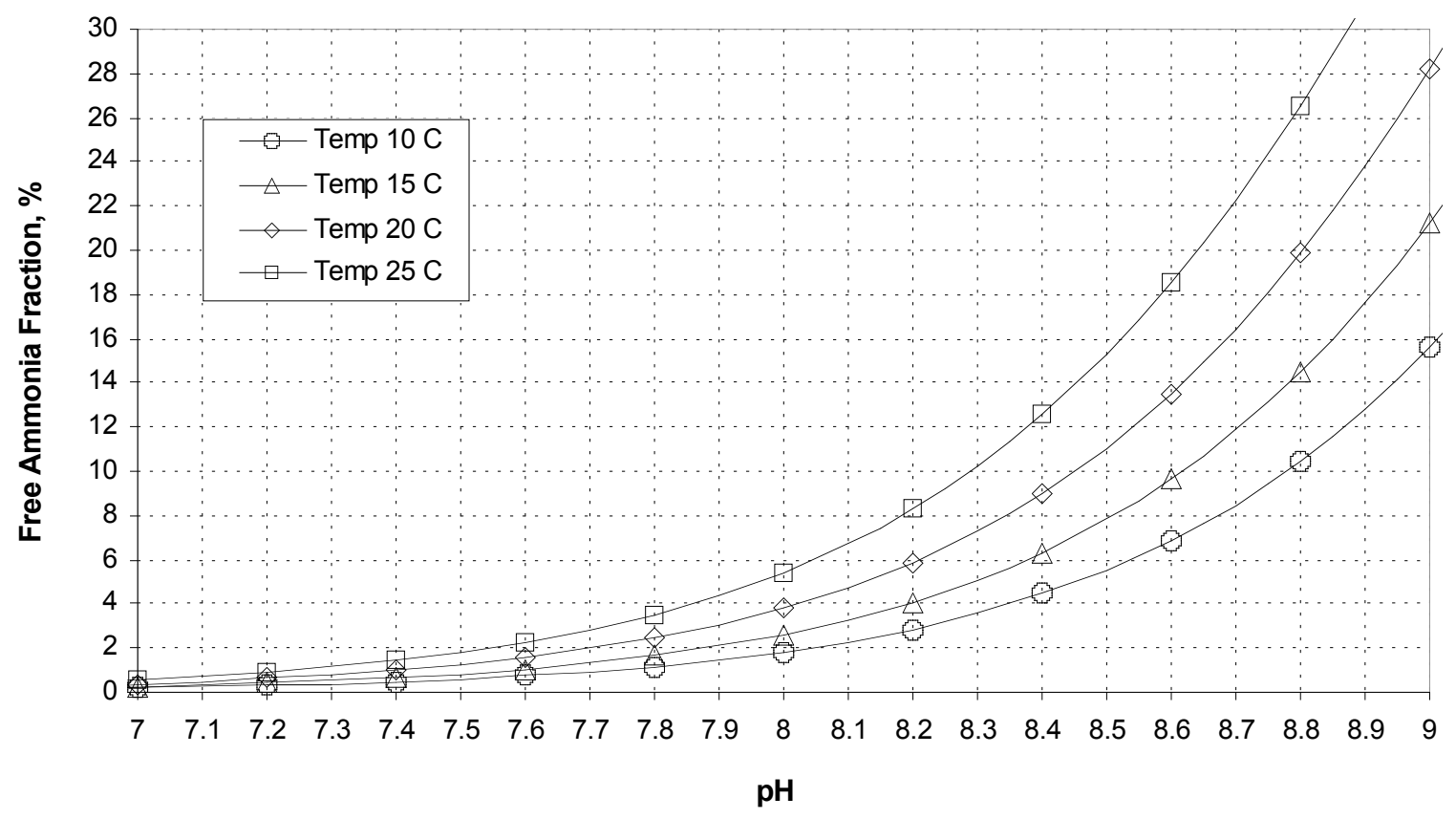




\section{Micronutrients}

The synthetic nature of the wastewater calls for verification of the availability of a number of micronutrients required for healthy microbial growth. The literature recommendations for the required micronutrients concentrations, as adjusted to the organic strength of the plant wastewater, are summarized in Table 1.

Table 1. Recommended Micronutrient Concentrations for Activated Sludge Treatment

\begin{tabular}{|l|l|l|l|l|l|l|l|l|l|l|l|}
\hline $\begin{array}{l}\text { Micronutrient } \\
\text { Concentration } \\
\text { micrograms/1 }\end{array}$ & $\mathrm{B}$ & $\mathrm{Co}$ & $\mathrm{Cu}$ & $\mathrm{Mn}$ & $\mathrm{Mo}$ & $\mathrm{Ni}$ & $\mathrm{Se}$ & $\mathrm{Zn}$ & $\mathrm{Ca}$ & $\mathrm{Mg}$ & $\mathrm{Fe}$ \\
\hline Reference 1 & N/A & 260 & 300 & 200 & 860 & $\mathrm{~N} / \mathrm{A}$ & 0.003 & 320 & 12,000 & 6,000 & 24,000 \\
\hline Reference 2 & 90 & 620 & 48 & 219 & N/A & 32 & N/A & 240 & 15,000 & 39,000 & 9,000 \\
\hline
\end{tabular}

1. Prorated for influent BOD of 2,000 mg/L (Eckenfelder and Musterman, 1995)

2. Micronutrients concentration used for pure Nitrobacter culture cultivation (Tang, 1992)

Analysis of the plant wastewater composition indicated that cobalt, molybdenum, nickel and ferric could be periodically deficient.

\section{CONCLUSIONS AND REMEDIAL MEASURES}

The main and immediate remedial measure was continuous addition of an ammonia source (urea) to the activated sludge process at a concentration of approximately $40 \mathrm{mg} / \mathrm{l}$ (as $\mathrm{N}$ ). This facilitated maintenance of an adequate population of nitrifiers as manifested by the presence of a minimum of $25 \mathrm{mg} / \mathrm{l}$ of nitrates in the effluent. No nitrification failures were registered since then.

Further recommended remedial measures, which are currently in the process of implementation, include minimization of organic loading to the aeration basin (and its variability), installation of a $\mathrm{pH}$ control system in the aeration basin, procurement of alum addition facilities for effluent polishing and micronutrients addition.

Additional investigations are under way to determine the identity of the nitrogen-bearing compound (or class of compounds), which appear to be very resistant to ammonification and could interfere with consistent and complete nitrification. 


\section{REFERENCES}

Stringfellow, W.T. (2003) Lawrence Berkeley National Laboratory at University of California, personal communication.

U.S. Environmental Protection Agency (1993) Nitrogen Control Manual; EPA/625/R-93/010, Washington, D.C.

U.S. Environmental Protection Agency (1987) Guidance Manual on the Development and Implementation of Local Discharge Limitations Under the Pretreatment Program; EPA, Washington, D.C.

U.S. Environmental Protection Agency (1978) Soluble Organic Nitrogen Characteristics and Removal; EPA-600/2-78-030, Washington, D.C.

Eckenfelder, W.W.; Musterman, J.L. (1995) Activated Sludge Treatment of Industrial Wastewater, Technomic Publishing Co.; Lancaster, Pennsylvania.

Dhillon J.K. and Shivaraman N. (1999) Biodegradation of Organic and Alkali Cyanide Compounds in a Trickling Filter, Indian J. Environmental Protection,

Tang N.H., et al. (1992) OSAR Parameters for Toxicity of Organic Chemicals to Nitrobacter. Journal of Environmental Engineering, 118 (1)

Blum D.J.W. and Speece, R.E. (1991) A Database of Chemical Toxicity to Environmental Bacteria and Its Use in Interspecies Comparisons and Correlations. Research Journal WPCF, 63 (3), 198. 